Journal of Engineering and Applied Sciences 14 (Special Issue 9): 10673-10677, 2019

ISSN: 1816-949X

(C) Medwell Journals, 2019

\title{
Preparation of Nano Films from ZnO/MWCNT and Study their Applications as a Gas Sensor
}

\author{
${ }^{1}$ Mohammed Hadi Shinen, ${ }^{2}$ Raheem Abed Jeber and ${ }^{3}$ Burak Kadem \\ ${ }^{1}$ Department of Science, College of Basic Education, PO. Box 4, University of Babylon, \\ Hillah, Iraq \\ ${ }^{2}$ Department of Physics, College of Education, Qadisiya University, Al Diwaniyah, Iraq \\ ${ }^{3}$ Department of Physics, College of Science, University of Babylon, Hillah, Iraq
}

\begin{abstract}
Thin nanoparticles of zinc oxide were prepared using sol-gel. "The samples were prepared nano thin film $(71 \mathrm{~nm})$, various weight ratios were added from the MWCNT to the colloidal solution and at a rate of" " $(0.423,0.921,1.624 \%)$. These solutions were deposited by using the spin coating technique on the glass substrate and interdigitated finger electrode. For the purpose of knowing the sensitivity and the extent of response of these samples to detect the different vapors of some toxic gases (ethanol, methanol, acetone and nitrogen). Nano thin film were prepared by using spin coting technique. The synthetic properties of these membranes were studied using X-ray diffraction.
\end{abstract}

Key words: ZnO, MWCNT, vapors, sensor, thickness, interdigitated

\section{INTRODUCTION}

Zinc Oxide $(\mathrm{ZnO})$ is at the forefront of semiconductor compounds II-VI with potential applications due to the high optical transmittance in the visible region due to its large band gap and electrical conductivity at room temperature; these characteristics make it an ideal candidate for applications such as transparent conductive electrode, window layers in the solar cell applications and gas sensors (Wang, 2004; Fan and Lu, 2005; Shinen, 2014). The nanoscale structure of zinc oxides plays an important role in the devices performance as an example in gas sensor devices because the large area will enhance the properties of gas sensors and moreover have safe biological properties (as a non-toxic substance) which makes $\mathrm{ZnO}$ very attractive for vital applications. The simple preparation methods of producing $\mathrm{ZnO}$ thin films give them the potential to be studied (Battez et al., 2008; Wu et al., 2009). ZnO can be applied as thin layers in transistor applications (Ohya et al., 2001) and is considered a rotational electronic material (Sharma et al., 2004). Zinc oxide films can be prepared using various techniques including lamination, chemical vapor, sol-gel and pyrolysis spray (Moustaghfir et al., 2003; Paraguay et al., 1999; Dinghua et al., 1998). Recently, due to its excellent physical properties and potential technological applications, $\mathrm{ZnO}$ has attracted considerable attention (Akkilic et al., 2012). ZnO is
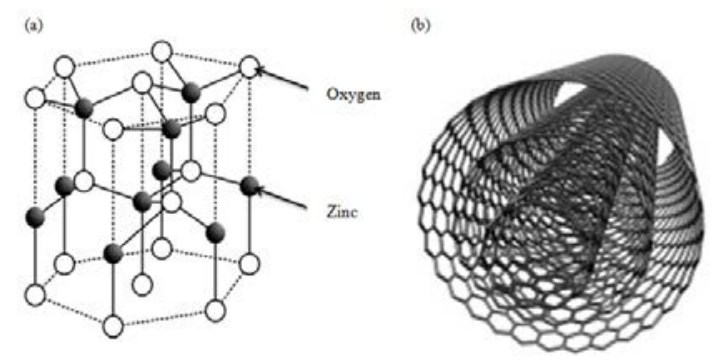

Fig. 1(a, b): Wurtzite structure of $\mathrm{ZnO}$ and (b) Multi-walled carbon nanotubes

an n-type semiconductor with wurtzite structure of hexagonal crystals (Jagadish and Pearton, 2007) as shown in Fig. 1a. O2-crystals can be described as tetrahedral and $\mathrm{Zn}^{2}+$ ions consist of alternately flat, stacked (Pearton et al., 2005). On the other hand, carbon based materials such as Multi-Walled Carbon Nanotubes (MWCNTs) which has significant applications in the field of sensors as well as other electronic devices due to the large area; the MWCNT includes a plurality of tubes in a concentric cylinder as shown in Fig. 1b (Abdulridha, 2015; Dresselhaus et al., 2001); the number of concentric walls can range from 6-25 or more. The diameter of the MWCNT can be about $30 \mathrm{~nm}$ compared to $0.7-2.0 \mathrm{~nm}$ for a typical SWCNT. The unique properties of carbon nanotubes make it possible for a wide range of novel applications and existing performance improvements (Abdulridha, 
2015; Dresselhaus et al., 2001). Un-doped ZnO has high conductivity due to the crystalline defects that contribute to a number of secondary levels between the valence and conduction bands. On the other hand, doping $\mathrm{ZnO}$ is to improve the stability of $\mathrm{ZnO}$ and further increase the electrical conductivity as an example, doping with MWCNTs. Such thin film has high permeability in the visible region of the spectra and low resistance; the optical energy gap can be controlled by the concentration of doping material added to the $\mathrm{ZnO}$ (Jeong et al., 2007). The latter enhancement can be used in improving the characteristics of different applications such as solar cells, coatings and chemical sensor devices (Nishino et al., 1992; Mondal et al., 2008).

\section{MATERIALS AND METHODS}

\section{Experimental section}

Sol-gel preparation of ZnO: Firstly, $4 \mathrm{~mL}$ of isopropanol is placed on a stirrer following by adding $50 \mu \mathrm{L}$ of Ethanolamine (MEA) under stirring for $30 \mathrm{~min}$ at $60^{\circ} \mathrm{C}$ to obtain the blending process of the solvents. Afterward, zinc acetate has been added to the solvent's mixture under stirring and the process was kept for $1 \mathrm{~h}$ at $60^{\circ} \mathrm{C}$. The final solution was kept in a sealed beaker (using paraffin paper to prevent the penetration of dust and moisture into the colloidal solution) at room temperature for $24 \mathrm{~h}$ in laboratory conditions to obtain transparent and homogeneous viscous fluid.
Preparation of sol-gel for the $\mathrm{ZnO} / \mathrm{MWCNT}$ (doped zinc oxide): Composite material based on mixing ZnO with MWCNTs has been carried out. After the preparation of sol-gel solution of pure $\mathrm{ZnO}$, a specific amount of MWCNTs were added to the $\mathrm{ZnO}$ solution to obtain the final mixture. The ratios of mixing were about $(0.423,0.921,1.624 \%)$ of MWCNTs in ZnO solution.

Preparation of samples: Clean glass slides were used after immersing them in ethanol for half an hour and then washed with distilled water three times after which the slides were placed in a thermocouple oven up to a degree $50^{\circ} \mathrm{C}$ for drying. Pure and MWCNTs-doped ZnO thin films were prepared using spin coatingmethod on pre-cleaned glass substrates. The solution is deposited on the sedimentation base during deposition. Then the sample is raised and placed on a hot plate at $60^{\circ} \mathrm{oC}$ until the solvent volatiles and the membrane dry. These samples are then placed in a furnace at $450^{\circ} \mathrm{C}$.

\section{RESULTS AND DISCUSSION}

AFM images: The results of the tests (AFM) of the nano films for pure $(\mathrm{ZnO})$ and doped with different ratio of (MWCNTS) films which prepared by spin coating which showed a uniform granular surface morphology as in Fig. 2a-d. Where we note that the roughness increased with increasing the ratio of doped (Srinivas et al., 2012; Tokarsky et al., 2012).
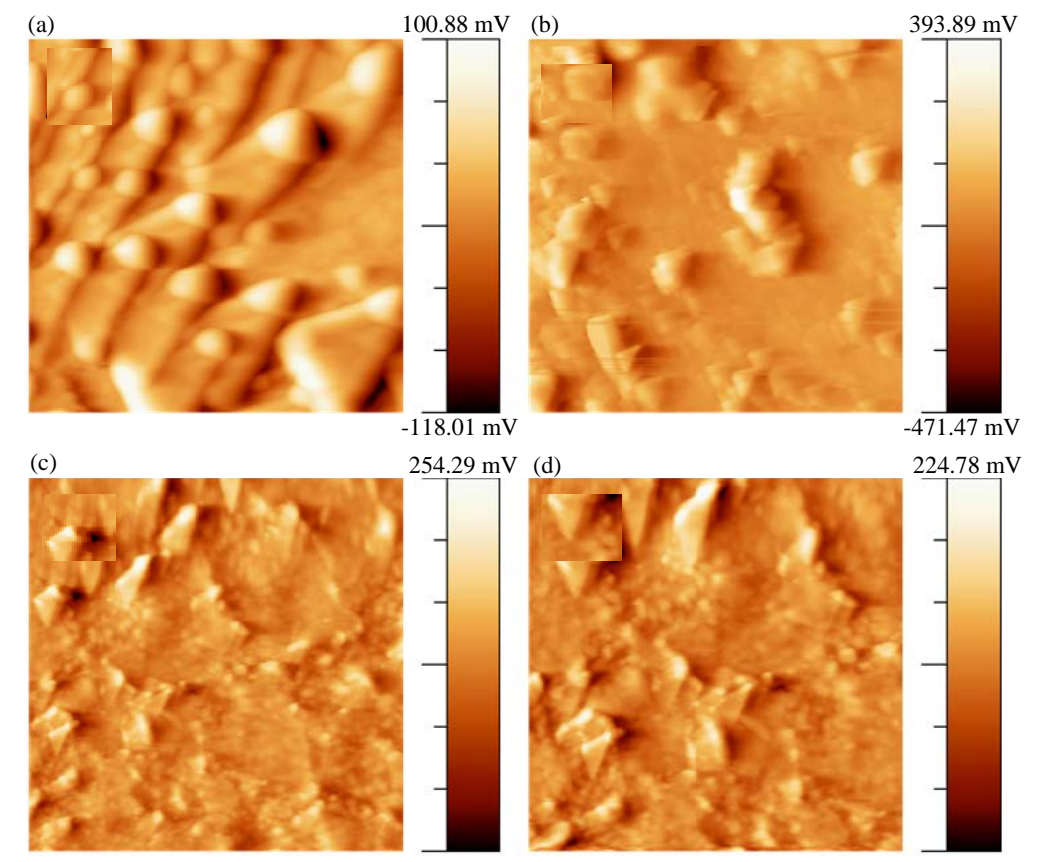

$254.29 \mathrm{mV}$ (d)
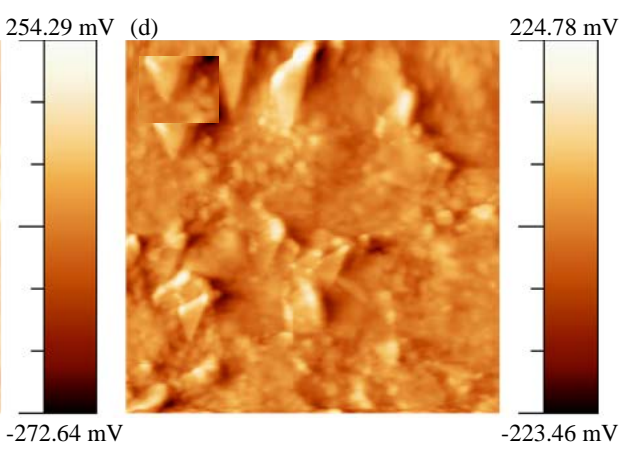

Fig. 2(a-d): AFM images for the ZnO based thin films, (a) pure, (b) 0.423\% MWCNTs, (c) 0.921\% MWCNTs and (d) $1.624 \%$ MWCNTs 

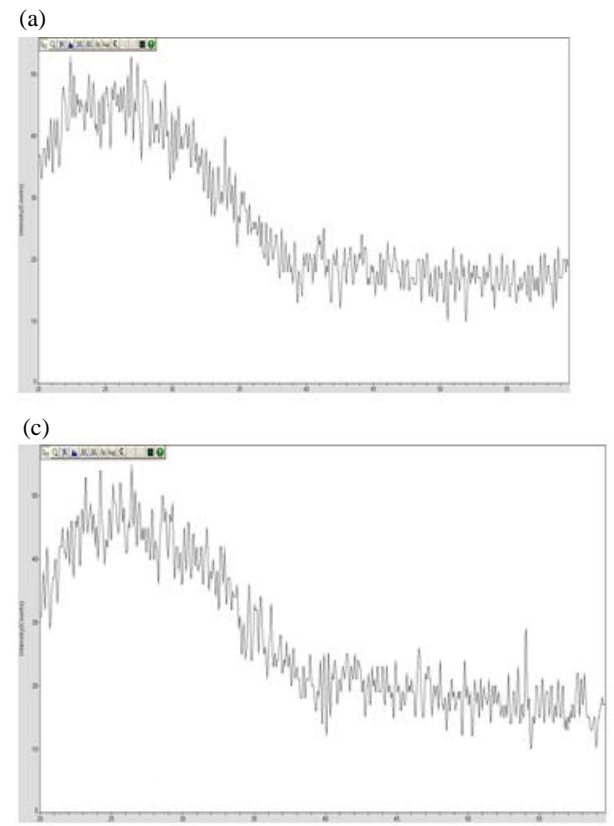

(b)
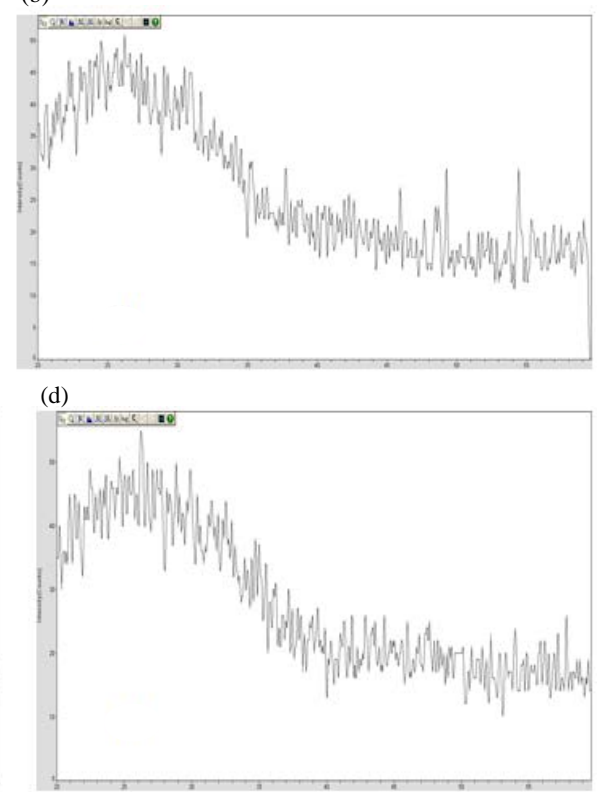

Fig. 3(a-d): XRD patterns for the ZnO based thin films, (a) pure, (b) 0.423\% MWCNTs, (c) 0.921\% MWCNTs and (d) $1.624 \%$ MWCNTs

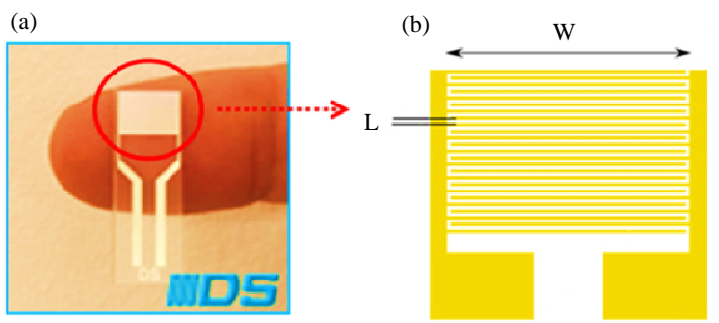

Fig. 4(a, b): Interdigitated electrodes used for the sensor

XRD analysis: $\mathrm{ZnO}$ membranes were examined with different fish $(62,71,85)$ and at temperature $\left(450^{\circ} \mathrm{C}\right)$ and $\mathrm{ZnO} / \mathrm{MWCNT}_{\mathrm{s}}$ membranes with different deflection ratios, using X-ray diffraction $(0.423$, $0.921,1.624 \%)$.

Figure 3a which represents the X-ray diffraction of pure $\mathrm{ZnO}$, appears broad summit at $(31,32)$ while Fig. 3(b-d) represents $\mathrm{X}$-ray diffraction of the $\mathrm{ZnO}$ doped by Carbon nanotubes with ratio $0.423 \%$ where notes the appearance of two peaks at $\left(5-30^{\circ}\right)$. An angle $\left(5^{\circ}\right)$ shows the diffraction for the parallel levels in the polymeric chain, an angle $\left(30^{\circ}\right)$ shows the diffraction of the levels orthogonal.

And Fig. 4 appear tested for the films with the ratio $(0.921,1.624 \%)$ where all films are show to have a random structure. These results are identical to the results of the researchers (Diaz-Sanchez et al., 2017; Chandra et al., 2017; Bhagwat et al., 2016).
Sensor response: The electrical conductivity was carried out using Interdigitated platinum Electrodes (IDEs) purchased from DropSens (Spain) (Fig. 4a and b). The IDE can be used to measure the surface conductivity $(\sigma)$ of the samples from the following relationship (Kadem et al., 2015):

$$
" \sigma=\frac{1}{\mathrm{~V}}\left(\frac{\mathrm{n}}{\mathrm{WtL}}\right) "
$$

Where:

$\mathrm{t} \quad$ : The thickness of the film $(\sim 100 \mathrm{~nm})$

$\mathrm{W}$ : The distance between the fingers $(6.67 \mathrm{~mm})$

$\mathrm{n} \quad$ : The number of fingers (500)

L : $\quad$ The distance between electrodes $(5 \mu \mathrm{m})$

Figure 5 shows that the sensitivity increases with the increased concentration of injected solutions when exposed to ammonia gas vapor and the amount of $20 \mu \mathrm{m}$ in the beginning and in all cases and then open the air to volatilize the gas molecules and then increase the amount of vapor gas injected and all cases.

By observing the above shapes, the response of the thin film to the gas vapor is increased by increasing the rate of deflection. This explains our interpretation of the membrane through the image of AFM. 

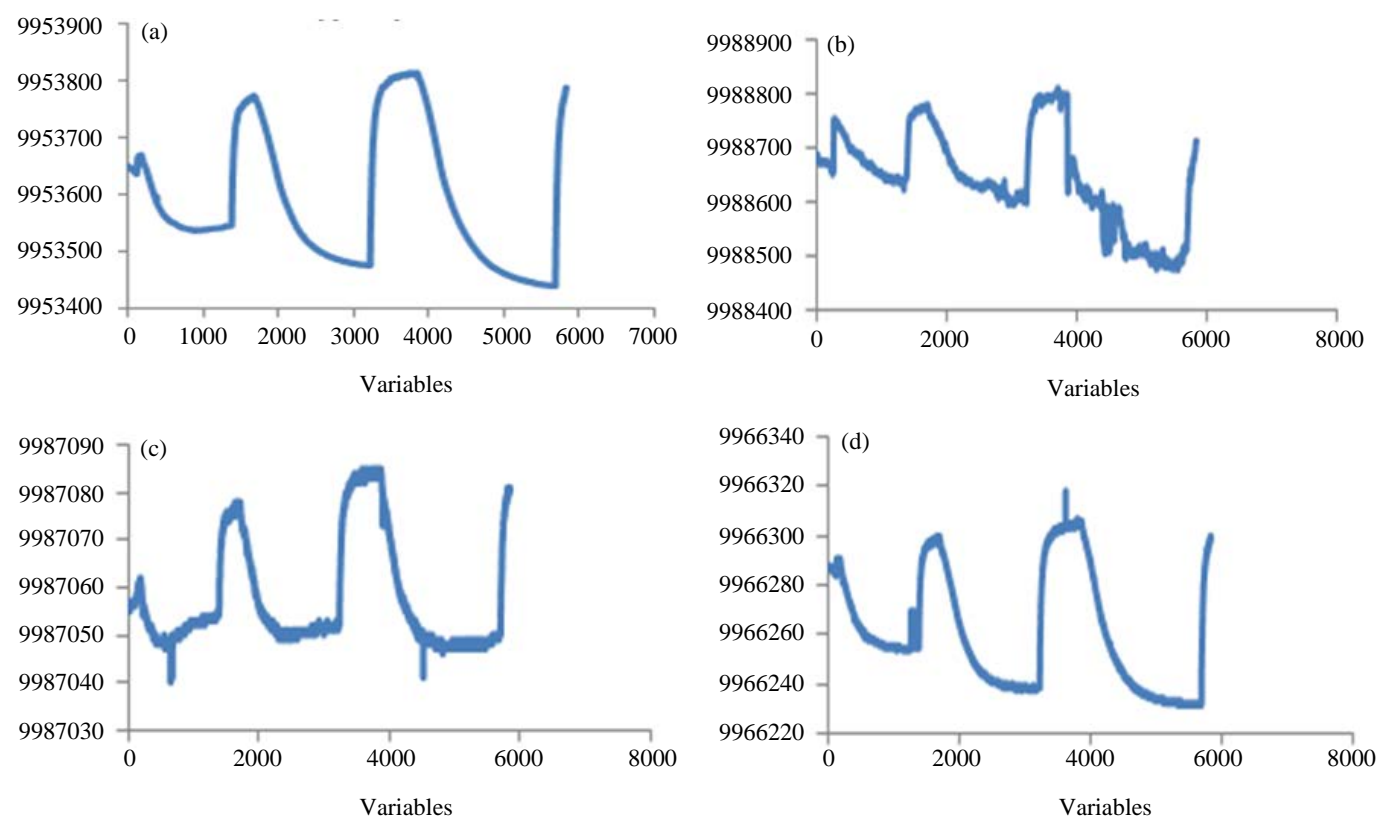

Fig. 5(a-d): Sensitivity of membranes to ammonia gas vapor, (a) ZnO (pure), (b) ZnO/MWCNT 1.624, (c) ZnO/MWCNT 0.921\% and (d) ZnO/MWCNT 0.423\%

\section{CONCLUSION}

The results showed that the prepared membranes were crystallized and close to the standard values. Among the AFM samples, the surface roughness was increased, making it more sensitive. The ability of the response of the ZnO/MWCNT membranes to all fish to respond to the fumes of these gases was studied. The highest response was found in the ethanol vapor and at the thickness $71 \mathrm{~nm}$ and at the weight ratio $1.624 \%$ " for methanol.

\section{REFERENCES}

Abdulridha, W.M., 2015. Fabrication and characterization study of CNTs/ PSiPhotodetector. Ph.D Thesis, University of Babylon, Hillah, Iraq.

Akkilic, K., Y.S. Ocak, T. Kilicoglu and A. Toprak, 2012. The annealing effects of $\mathrm{ZnO}$ thin films on characteristic parameters of $\mathrm{Au} / \mathrm{ZnO}$ schottky contacts on n-Si. J. Nano Electron. Phys., 4: 01012-1-01012-3.

Battez, A.H., R. Gonzalez, J.L. Viesca, J.E. Fernandez and J.D. Fernandez et al., 2008. $\mathrm{CuO}, \mathrm{ZrO} 2$ and $\mathrm{ZnO}$ nanoparticles as antiwear additive in oil lubricants. Wear, 265: 422-428.

Bhagwat, A.D., S.S. Sawant and C.M. Mahajan, 2016. Facile rapid synthesis of polyaniline (PANI) nanofibers. J. Nano. Electron. Phys., 8: 01037-1-01037-3.
Chandra, S., R. Bharadwaj and S. Mukherji, 2017. Label free ultrasensitive optical sensor decorated with polyaniline nanofibers: Characterization and immunosensing application. Sens. Actuators B. Chem., 240: 443-450.

Diaz-Sanchez, J., A. Rosas-Aburto, E. Vivaldo-Lima, J.M. Hernandez-Alcantara and I. Gracia-Mora et al., 2017. Development and characterization of a flexible electrochromic device based on polyaniline and enzymatically synthesized poly (gallic acid). Synth. Met., 223: 43-48.

Dinghua, B., H. Gu and A. Kuang, 1998. Sol-gel-derived c-axis oriented $\mathrm{ZnO}$ thin films. Thin Solid Films, 312: 37-39.

Dresselhaus, M.S. G. Dresselhaus and P. Avouris, 2001. Carbon Nanotubes: Synthesis, Structure, Properties and Applications. Springer, Berlin, Germany, ISBN:3-540-41086-4, Pages: 449.

Fan, Z. and J.G. Lu, 2005. Zinc oxide nanostructures: Synthesis and properties. J. Nanosci Nanotechnol., 5: 1561-1573.

Jagadish, C. and S.J. Pearton, 2006. Zinc Oxide Bulk, Thin Films and Nanostructures: Processing, Properties and Applications. Elsevier, Amsterdam, Netherlands, ISBN:9780080447223, Pages: 589.

Jeong, S.H., B.N. Park, D.G. Yoo and J.H. Boo, 2007. Al-ZnO thin films as transparent conductive oxides: synthesis, characterization and application tests. J. Korean Phys. Soc., 50: 622-625. 
Kadem, B., W. Cranton and A. Hassan, 2015. Metal salt modified PEDOT: PSS as anode buffer layer and its effect on power conversion efficiency of organic solar cells. Org. Electron., 24: 73-79.

Mondal, S., K.P. Kanta and P. Mitra, 2008. Preparation of Al-doped $\mathrm{ZnO}$ (AZO) thin film by SILAR. J. Phys. Sci., 12: 221-229.

Moustaghfir, A., E. Tomasella, S.B. Amor, M. Jacquet and J. Cellier et al., 2003. Structural and optical studies of $\mathrm{ZnO}$ thin films deposited by r.f. magnetron sputtering: Influence of annealing. Surf. Coat. Technol., 174: 193-196.

Nishino, J., S. Ohshio and K. Kamata, 1992. Preparation of aluminum-doped zinc oxide films by a normal-pressure CVD method. J. Am. Ceram. Soc., 75: 3469-3472.

Ohya, Y., T. Niwa, T. Ban and Y. Takahashi, 2001. Thin film transistor of $\mathrm{ZnO}$ fabricated by chemical solution deposition. Japn. J. Appl. Phys., 40: 297-298.

Paraguay, F.D., W.L. Estrada, D.R.N. Acosta, E. Andrade and M. Mikiyoshida, 1999. Growth, structure and optical characterization of high quality $\mathrm{ZnO}$ thin films obtained by spray pyrolysis. Thin Solid Films, 350: 192-202.
Pearton, S.J., D.P. Norton, K. IP, Y.W. Heo and T. Steiner, 2005. Recent progress in processing and properties of ZnO. Prog. Materials Sci., 50: 293-340.

Sharma, P., A. Gupta, F.J. Owens, A. Inoue and K.V. Rao, 2004. Room temperature spintronic material-Mn-doped $\mathrm{ZnO}$ revisited. J. Magn. Magn. Mater., 282: 115-121.

Shinen, M.H., 2014. Preparation of nano-thin films of $\mathrm{ZnO}$ by sol-gel method and applications of solar cells hetrojunction. J. Nat. Sci. Res., 4: 98-106.

Srinivas, C.H., D. Srinivasu, B. Kavitha, N. Narsimlu and K.S. Kumar, 2012. Synthesis and characterization of nano size conducting polyaniline. IOSR. J. Appl. Phys., 1: 12-15.

Tokarsky, J., K.M. kutlakova, V. Styskala, L. Neuwirthova and L. Kulhankova et al., 2012. Structure analysis of pani pressed pellets using X-ray diffraction and molecular modeling. Proceedings of the 4th International Conference on NANOCON 2012, October 23-25, 2012, RCPTM, Brno, Czech Republic, pp: 1-6.

Wang, Z.L., 2004. Zinc oxide nanostructures: Growth, properties and applications. J. Phys.: Condens. Matter, 16: R829-R858.

Wu, D., Z. Bai and K. Jiang, 2009. Temperature induced hierarchical growth of $\mathrm{ZnO}$ microcrystal. Mater. Lett., 63: 1057-1060. 